Distribution

\title{
DEMONSTRATION OF HIGH-RESOLUTION INVERSE VSP FOR RESERVOIR CHARACTERIZATION APPLICATIONS
}

\author{
Quarterly Report for the Period \\ January-March 1991
}

By Jorge O. Parra OCT 071991

Work Performed Under Contract No. AC22-89BC14473

\author{
Robert E. Lemmon, Project Manager \\ Bartlesville Project office \\ P. O. Box 1398 \\ Bartlesville, OK 74005
}

\section{MASTER}

\author{
DISTRIBUTION OF THIS DOCUMENT IS UNLIMITED \\ $y^{x}$ \\ Prepared by \\ Southwest Research Institute \\ P. O. Drawer 28510 \\ San Antonio, TX 78228-0510
}

\section{DISCLAIMER}

This repon was prepared as an account of work sponsored by an agency of the United States Government. Neither the United States Government nor any agency thereof, nor any of their employees, makes any warranty, express or implied, or assumes any legal liability or responsibility for the accuracy, completeness, or usefulness of any information, apparatus, product, or process disclosed, or represents that its use would not infringe privately owned rights. Reference here $n$ to any specific commercial product, process, or service by trade name, trademark, manufacturer, or otherwise does not necessarily constitute oi imply its endorsement, recom. mendation, or favoring by the United States Government or any agency thereof. The views and opinions of authors expressed herein do not necessarily state or reflect those of the United States Government or any agency thereof. 


\section{OBJECTIVE}

The objective of this project is the demonstration of inverse vertical seismic profiling measurements using new experimental field instrumentation capable of providing at least an order of magnitude improvement in the resolution of structural details in comparison with conventional seismic images. This two-year project will entail instrumentation tests under controlled field conditions during the first year followed by full-scale field demonstration tests in a representative oil-bearing reservoir formation during the second year.

\section{SUMMARY OF TECHNICAL PROGRESS}

\section{Work Accomplished}

An automatic time-picking program and a tomographic inversion program developed for processing interwell seismic data were generalized for processing reverse VSP data. In order to demonstrate the use of these computer cajabilities, the X-component seismogram given in Figure 1 was processed and edited using the automatic time-picking program. The seismic waveforms in Figure 1 were recorded using a wax-embedded 3-component detector at the SwRI borehole test facility. The resulting first P-wave arrival time as a function of depth are illustrated together with the reverse VSP seismic waveforms in Figure 2.

Since the geological formations at SwRI are a combination of limestones, mudstones, shales, and dolomites in the horizontally stratified layer medium, we assumed for the velocity inversion that the earth is formed by a sequence of discrete horizontal layers. The result of this inversion is shown in Figure 3.

In general, a good agreement between the geological logs and inversion result was obtained. In Figure 3, the limestone/clean limestone contact at a depth of $30 \mathrm{~m}$ correlates with the slowness peak of about $575 \mu \mathrm{sec} / \mathrm{m}(1739 \mathrm{~m} / \mathrm{sec})$. Also, the strong increase in slowness of about $850 \mu \mathrm{sec} / \mathrm{m}(1175 \mathrm{~m} / \mathrm{sec})$ is associated with the limestone/Austin chalk boundary at a depth of $71 \mathrm{~m}$. This boundary separates the limestone layer of higher velocity and the low-velocity bottom formation in the water table.

A technical paper was submitted for publication to Geophysics. The paper is entitled: "A Wax-Embedded Borehole Seismic Detector for High-Resolution Measurements." A copy of this manuscript is enclosed in the Appendix.

\section{Work Anticipated}

We are planning to conduct the full-scale reverse VSP experiments in the month of August at the Buckhom test facility in southern Illinois near the city of Cooperstown. The shallow seismic test site has a stratified geology. A producing hydrocarbon reservoir at a depth of about 700 feet presents a reasonable seismic target. The hydraulically clamped detector probe developed for this project and a mechanical wall-lock seismic detector probe being developed by the Institute for the Bureau of Mines will be used for the reverse VSP

experiments. The borehole wall-lock seismic detector will be loaned for the experiments to the Institute by the Bureau of Mines. Since the hydraulically clamped detector probe was developed to conduct field experiments in boreholes no deeper than $80 \mathrm{feet}$, the mechanical wall-lock probe will be used in boreholes deeper than 80 feet. 


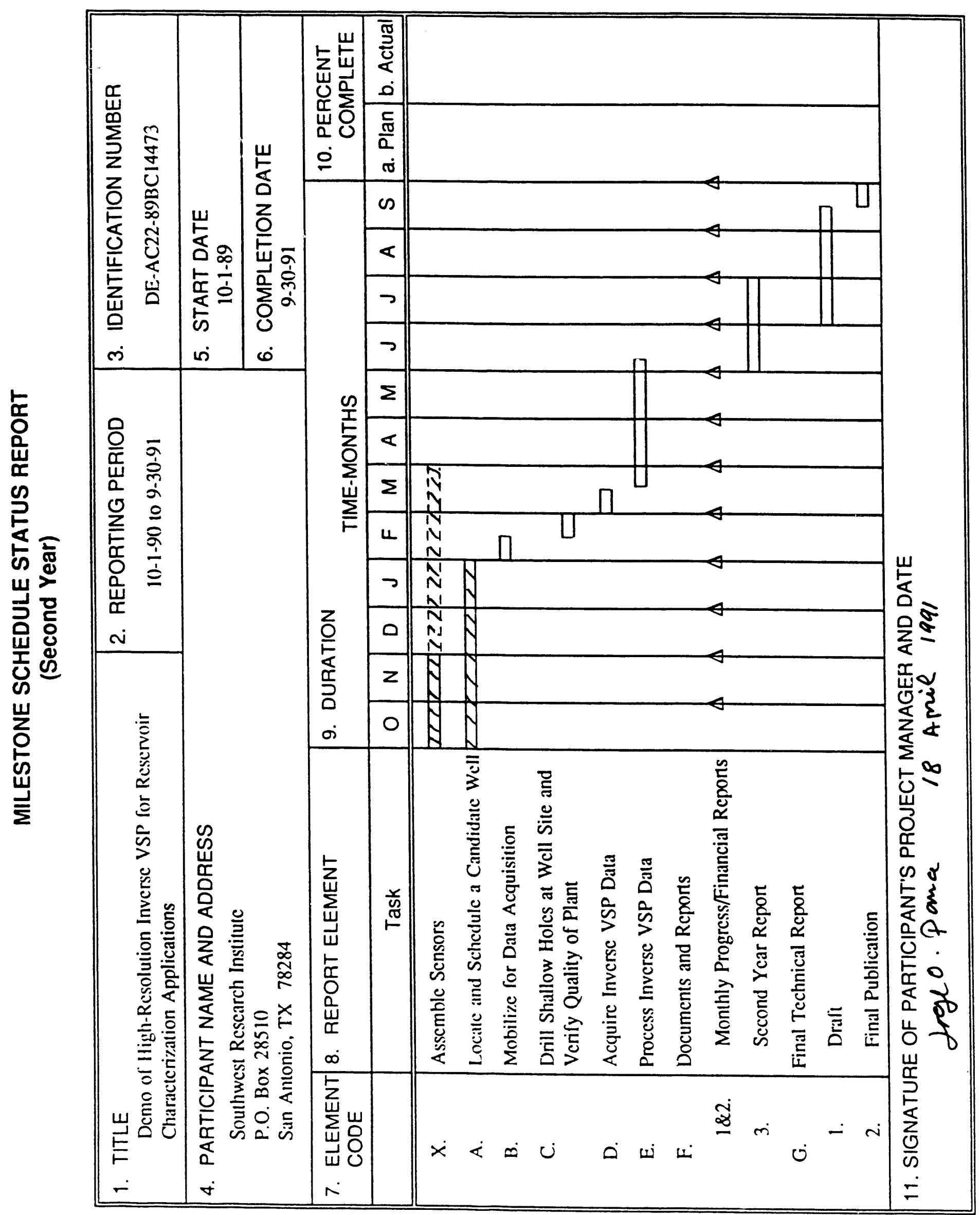




$$
\text { ¿ary 750 -. } \because \text { component }
$$

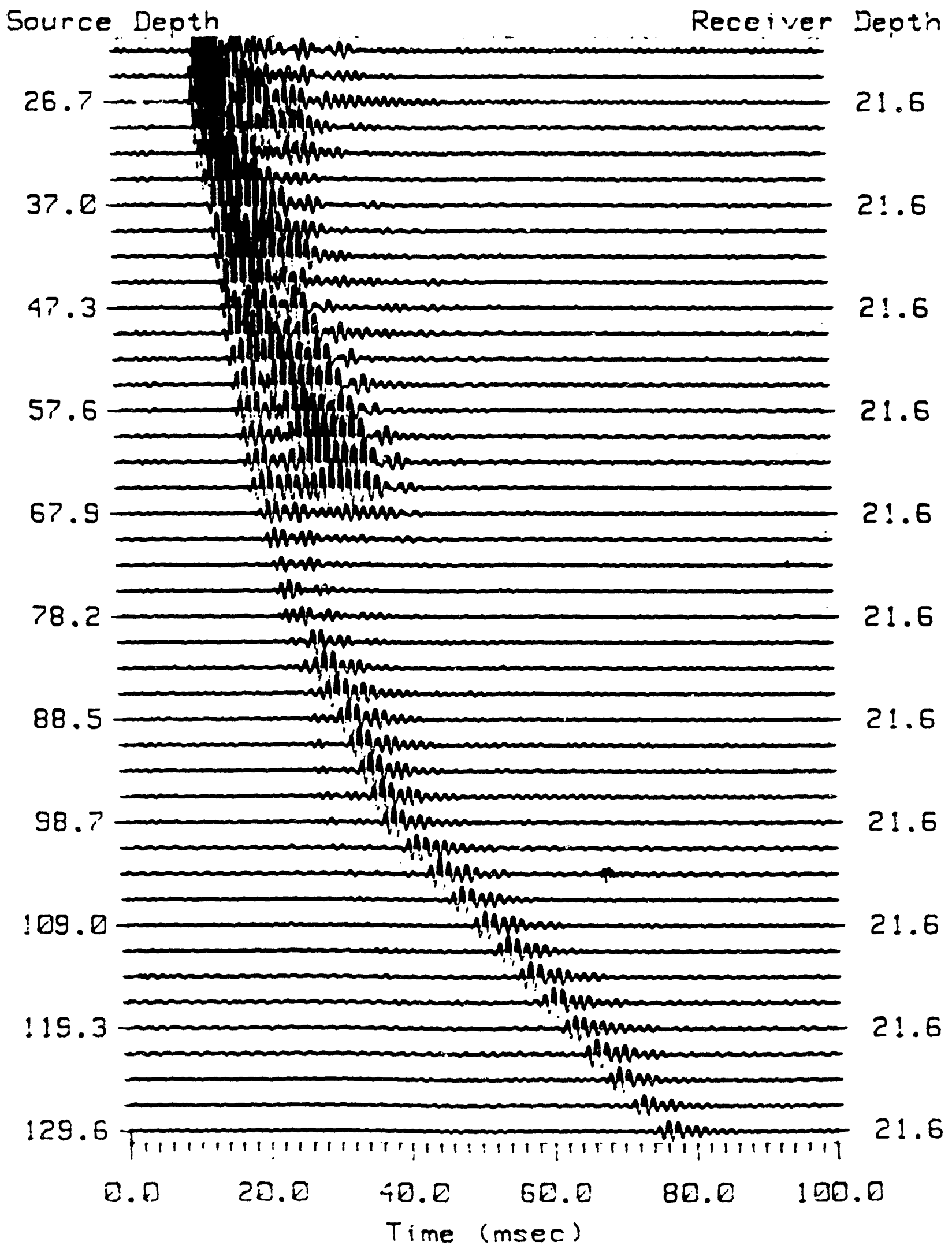

FIGURE 1. X-COMPONENT WAX-EMBEDDED DETECTOR SEISMOGRAM SHOT POINTS OBTAINED AT A SOURCE CENTER FREQUENCY OF $705 \mathrm{~Hz}$ 


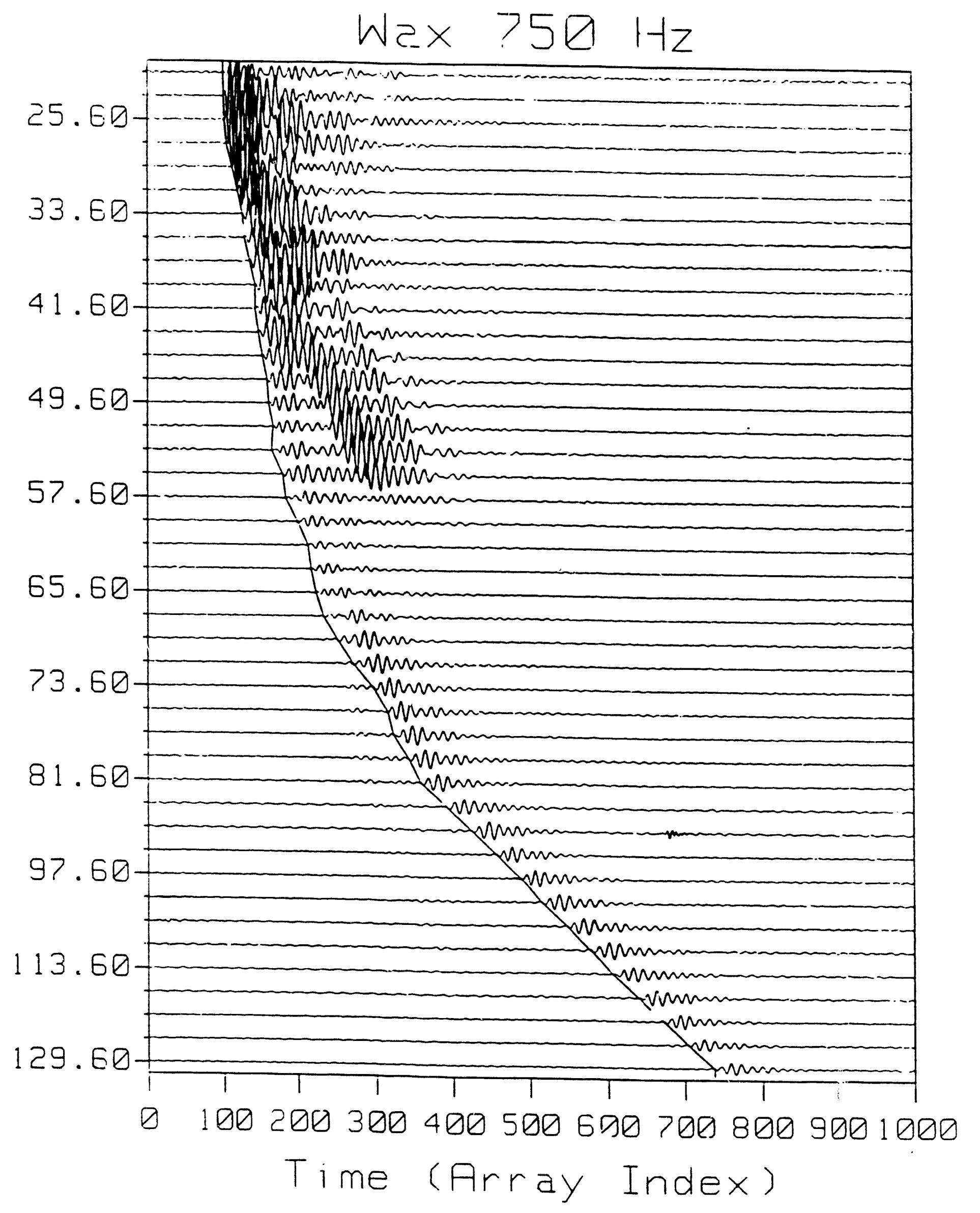

FIGURE 2. REVERSE VSP DATA OF FIGURE I SHOWING FIRST ARRIVAL TIMES AS A FUNCTION OF DEPTH. THE ARRIVAL TIMES WERE GBTAINED BY USING THE AUTOMATIC TIME-PICKING PROGRAM. 


\section{Wax Detector - $750 \mathrm{~Hz}$}

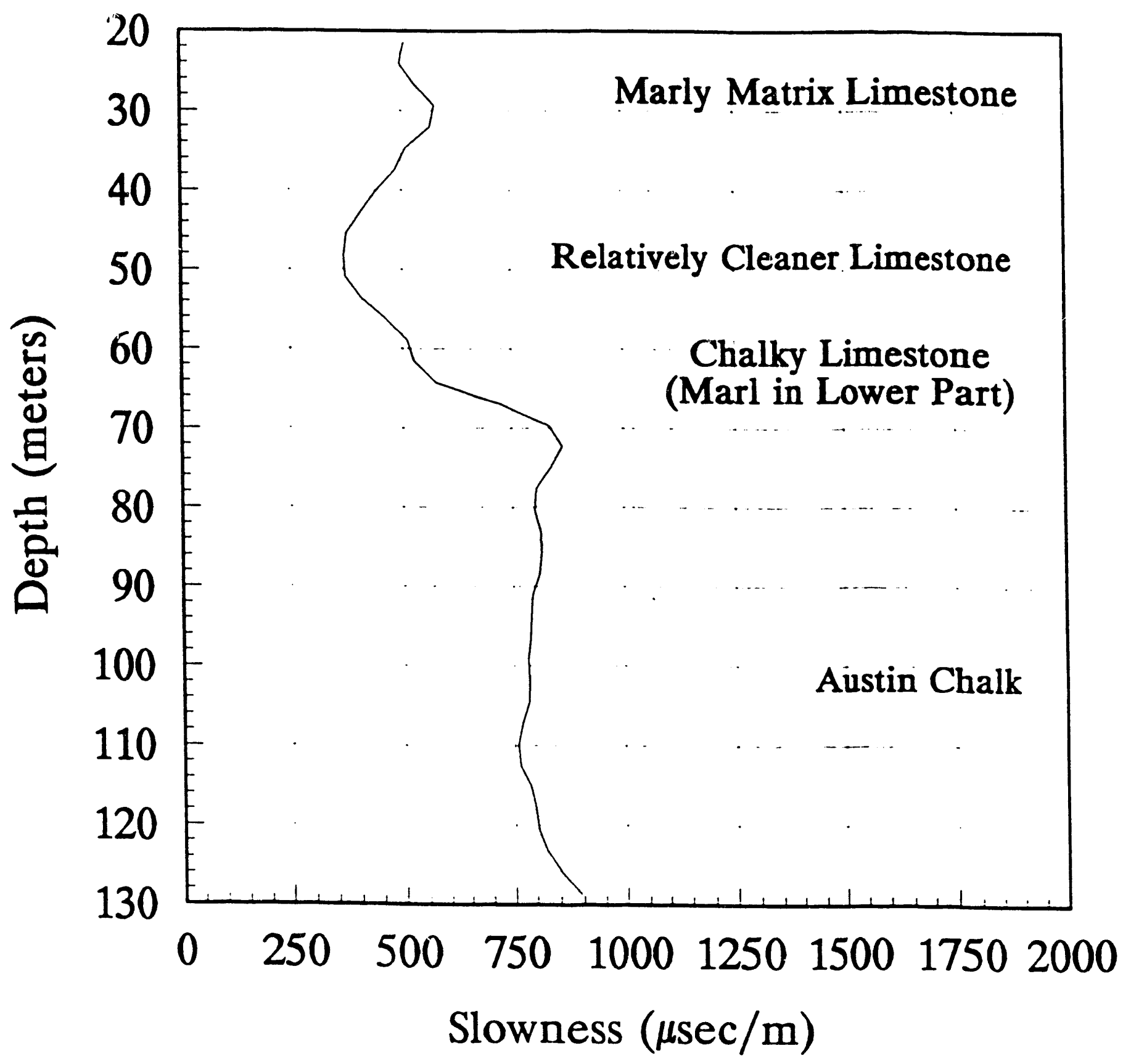

FIGURE 3. STRAIGHT RAY VELOCITY INVERSION. THE RESULTING VERTICAL SLOWNESS PROFILE AS A FUNCTION OF DEPTH. 


\section{A WAX-EMBEDDED BOREHOLE SEISMIC DETECTOR FOR HIGH-RESOLUTION MEASUREMENTS}

By

Thomas E. Owen

and

Jorge O. Parra

Southwest Research Institute San Antonio, Texas 78228-0510

Duplication rights pre-reserved. This paper is submitted to the Society of Exploration Geophysicists for publication. This is an unedited preprint, subject to later revision. 


\begin{abstract}
Seismic measurements are now being extended well above the conventional frequency limit of about 150-200 $\mathrm{Hz}$ often considered to be the extended spectral range for highresolution exploration work. Indeed, seismic source and detector technology has exceeded the kilohertz frequency limit in applications such as interwell seismic imaging, shallow reflection surveys, and reverse vertical seismic profiling. High-resolution measurements demand highquality data; meaning wideband frequency response, the highest practical signal-to-noise ratio, precision response uncluttered by arifacts related to the source or detector plants, and more complete information content afforded by both compressional and shear wave measurements. While sources and detectors are both critical to this goal, we address the need for precision seismic measurements at this time since source technology developments are already receiving significant attention.
\end{abstract}

Artifact-free seismic measurements at frequencies up to about $2,000 \mathrm{~Hz}$ are needed if a projected high-resolution limit on the order of one meter in spatial dimensions is to be realized in reservoir structure delineation, crosswell sonic logging, and shallow reverse VSP applications. For this reason, $w^{r}$ xamined the detector requirement from an objective view as well as from a transitional view, seeking, first, a practical methodology that could meet the various demands of high-resolution measurements. The result was a prototype reference detector capable of demonstrating state-of-the-art wide bandwidth response and data quality up to the high frequency limits of interest.

Our approach to this ideal detector uses a triaxial accelerometer sensor probe specialized to seismic applications installed in a borehole drilled through the lossy surface layer to the depth at which the ground is competent enough to support practical kilohertz wave propagation. This shallow borehole detector module is planted using a meltable wax embedment to achieve a very rigid and conformal coupling at the bottom of the hole while also being retrie'vable after the measurements are complete. Experimental test results show the wax-embedded detector to have excellent broadband 3-component response at frequencies in the range of $750-2,500 \mathrm{~Hz}$; a range heretofore unexplored for seismic applications. A second borehole 3-component detector probe, employing pneumatic coupling, was briefly tested under identical measurement conditions for comparison. Althe agh the pneumatically coupled probe exhibited a modal resonance in the highest frequency range, in reference to the wax-coupled detector, it was judged to provide an acceptable and useable response over the high-resolution frequency range of interest.

\title{
INTRODUCTION
}

Conventional seismic exploration has been very productive in delineating reservoirscale subsurface structures with spatial resolution on the order of 15-20 meters (upper frequency limit $100-150 \mathrm{~Hz}$ ). However, new seismic applications are now being sought which will have the capability of resolving oil and gas reservoir structure details to dimensions of approximately one meter, corresponding to an upper frequency limit of about $2,000 \mathrm{~Hz}$. Acoustic parameters measured in reservoir formations to this same resolution are also being explored to interpret the important rock physical properties of porosity, fluid permeability, and pore fluid or injection fluid migration pathways. These requirements are 
primarily relevant to interwell seismic measurements because of attenuation in the reservoir overburden but similar concepts are equally relevant to shallow high-resolution reverse VSP applications as well as to shallow reflection surveys in mining, engineering, and environmental applications.

A particular seismic application having high potential for reservoir delineation is highresolution reverse VSP in which a broadband seismic source is positioned at different depths in the well and the detectors carefully planted near the surface. Measurements in the frequency range of $500-2,000 \mathrm{~Hz}$ can image a significant volume of the subsurface immediately surrounding the well with a resolution on the order of 1-3 meters. Applied in shallow reservoirs, such reverse VSP observations will represent a new and important aid in achieving improved reservoir engineering and production.

We have recently developed new instrumentation for demonstrating high-resolution reverse VSP measurements (Parra and Owen, 1990). The work reported here had the goal of developing an effective high-resolution 3-component seismic detector capable of providing smooth arifact-free frequency response over the frequency range of $200-2,000 \mathrm{~Hz}$. The most significant factor influencing this goal is the fact that inelastic attenuation in the unconsolidated surface layer of the ground is excessively high and, therefore, must be avoided if effective kilohertz frequency response is to be achieved. For this purpose the detector probe must be placed in a shallow borehole drilled to the depth at which the ground is sufficiently rigid to transmit the high-frequency seismic waves. Other factors critical to this application are the physical coupling of the detector probe to the ground and the accuracy of the seismic sensing elements in responding to the three components of ground motion.

Significant work has been accomplished in characterizing and improving the response of borehole-coupled seismic detectors in the conventional frequency range of seismic signals (Wuenschel, 1988; Montmollin, 1988). These efforts emphasized the compact and lightweight physical design of the detector probe and used one or more self-contained shaker source to check the quality of the wall-lock coupling. Wuenschel (1988) used the shaker response as a means for removing the anomalous coupling response effects from 3-component VSP records and, as a result, identified the basic fact that the fundamental modal resonance of the coupled detector probe should be higher than the seismic frequency range of interest. Montmollin (1988) showed that relatively large VSP tools could meet this modal resonance criterion by assuring distributed multiple-point contact with the wellbore and that the shaker test could confirm the quality of coupling. From a more general view, Tan (1987) has pointed out that the elastodynamic response of a detector coupled to the ground will exhibit minimum distorion of the true ground motions when the mass of the detector probe is equal to the mass of the ground medium displaced by the probe volume. In combination, these probe design factors imply that the ideal detector should, in effect, replace the drilled formation in both conformal shape, mass density, and elastic rigidity.

The reported high-resolution detector probe was designed, to the extent practical, according to the above philosophy. In addition to being a small and lightweight detecto-, horehole coupling is accomplished by a meltable wax which solidifies to form a relatively stress-free rigid embedment of the probe that conforms exactly with the borehole shape. Accelerometer sensors are used to avoid the spurious transverse resonance responses of 
Accelerometer sensors are used to avoid the spurious transverse resunance responses of geophones in the frequency range of $300-1,000 \mathrm{~Hz}$ and higher and to provide the maximum practical rejection of transverse excitation in the high-frequency operating range. When tested under controlled conditions, this detector configuration exhibits an exceptionally clear response to puised seismic signals in the frequency range of $750-2,500 \mathrm{~Hz}$; the frequency range in which it is primarily intended to operate. Comparisons with other detector probes equipped with the same acceleration sensors clearly demonstrates the effectiveness of the wax-melt coupling over other borehole coupling techniques. While not practical for use under all shallow borehole conditions, this wax-emplaced 3-component shallow borehole detector can serve as an ideal reference detector for evaluating other high-resolution borehole seismic detector probes.

\section{ACCELERATION DETECTORS AND WAX-EMBEDDED BOREHOLE COUPLING}

\section{Borehole Coupling Requirements}

High-resolution reverse VSP measurements require that 3-component vector seismic signals be detected and recorded at or near the ground surface at the highest practical frequencies. Seismic frequencies up to $2,000 \mathrm{~Hz}$ and higher are desirable in order to resolve small structural details in the geologic formations surrounding the borehole being surveyed. Critical factors to be considered in achieving such high-resolution three-dimensional vector seismic measurements include:

Seismic Sensors: The seismic detectors to be used in the 3-component measurements must have a smooth amplitude and phase response over the frequency range of approximately $200-2,000 \mathrm{~Hz}$ on the principal axis with low sensitivity to transverse vibration excitations. The transverse-axis sensitivity should be one percent or less relative to the sensitivity on the principal axis. Conventional geophones are not appropriate for use in this resnect because of spurious transverse resonances that typically occur in the frequency range of about 300-400 $\mathrm{Hz}$ for detectors having principal-axis natural resonances in the range of 10-20 $\mathrm{Hz}$. and in the frequency range of about $600-800 \mathrm{~Hz}$ for high-frequency geophones (natural resonance in the range of 40-100 Hz) (Parra and Owen, 1990). These geophones typically exhibit a broadband transverse-axis sensitivity of at least 10 percent of the principal-axis sensitivity and, at spurious off-axis resonances, the transverse response increases to about $40-50$ percent for some models.

Acceleration detectors can provide the required uniform high-frequency response and transverse-axis isolation needed for the high-resolution reverse VSP seismic measurements. The sensor used in the wax-embedded detector is a prototype seismic accelerometer developed specifically for seismic field measurements in the frequency range of $200-2,000 \mathrm{~Hz}$ and having a transverse sensitivity of approximately 0.5 percent. A similar version of this sensor is now manufactured by Wilcoxon Research Corporation, Rockville, MD.

The combination of acceleration sensitivity and self-noise spestral density of this accelerometer results in a seismic detection threshold approximately c:quivalent to that of a 
hypothetica! geophone having a sensitivity of 1 vold/ips and 1200-ohm coil at a cross-over frequency of approximately $215 \mathrm{~Hz}$. At frequencies above $215 \mathrm{~Hz}$, the accelerometer provides a superior sensitivity and signal-to-noise ratio over that of the geophone. Below 215 $\mathrm{Hz}$, the geophone has superior performance.

Sensor Package: Three acceleration sensors must be mounted in an orthogonal array to provide the required vector seismic measurements of interest. The conventional orientation arrangement for these sensors when used in borehole applications is to align one sensor axis with the borehole axis (i.e., with the sensor package $Z$-axis) and to align the other two sensor axes along the $\mathrm{X}$ - and $\mathrm{Y}$-axes in the azimuthal plane of the sensor package. The mounting assembly containing the three sensors must be rigid and lightweight.

Sensor-to-Borehole Coupling: $\quad$ Although mechanical wall-locking sensor probes are used in conventional VSP surveys, wall-lock coupling is necessary to achieve temporary operation in the wellbore so that the well may be used later for its intended oil or gas production purpose. In high-resolution reverse VSP measurements, the seismic detectors are to be located in shallow boreholes drilled only to the depth at which high-frequency seismic waves can be detected without excessive attenuation. By coupling the detector elements to more competent rock in the subsurface rather than in the incompetent rocks at the surface the seismic bandwidth will be extended to the practical limit afforded by the field site conditions (Wuenschel, 1976).

\section{A Reversible Rigid-Coupling Method for Borehole Seismic Transducers}

The coupling method used in present-day borehole seismic detectors is one in which mechanical arms lock the probe in place for the temporary time period required for the measurements. In general, seismic wall-lock probes of this type have an average density which is much greater than the drilled rock formations and, therefore, a very high mechanical clamping force is required to couple these probes to the borehole wall. In practice, this technique is usually only parially successful because of imperfect borehole wall contact and spurious resonances that occur in the clamping mechanism.

Alternatively, permanent installation of the seismic detectors is occasionally desirable. A common practice used in such permanent installations is to embed the sensor in the borehole using prrtland cement or other rigid casting material. In this case, the seismic detector must be considered to be expendable since it cannot be recovered in a cost effective manner. Such permanent emplacements have been used in a number of field tests using relatively inexpensive geophones which could be abandoned in place when the tests were completed. This method has proven to be very effective in providing good seismic coupling by the fact that the cement forms a rigid and conformal casting in the borehole and the composite sensor and cement has a density which is reasonably well matched to that of the surrounding geological material.

The acceleration sensors mentioned above for reverse VSP measurements are significantly more expensive than geophones and, therefore, cannot be considered to be expendable. An alternative wax-melt coupling technique was developed to achieve the desirable results of rigid conformal borehole coupling, an approximate match between the average density of the 
sensor package and the drilled rock formation, and the ability to recover the sensor package (Parra and Owen, 1990).

\section{Wax Implanting Techniques}

Waxes of natural origin (e.g., vegetable ester composition) are used in bulk forms in commercial applications such as investment casting where rigidity and precision dimensions are important. Blends of these waxes have proven to be optimum in minimizing the thermal expansion that occurs on heating and the shrinkage that occurs on solidification. Waxes of this type have a specific gravity in the range of 0.97 to 1.05 and a melting point in the range of 178 to $190^{\circ} \mathrm{F}$. The shrinkage of such waxes on solidification varies widely from only a few percent up to about 30 percent. Therefore, provided that shrinkage can be minimized and that the borehole in which the wax-melt coupling is to be installed is not filled with water, a rigid wax embedment of the seismic sensor can serve as an alternative to portland cement so as to allow the sensor to be removed by remelting the wax.

Shrinkage can be controlled in the borehole sensor coupling application by designing the wax heat control process to provide staged vertical gradient heating and controlled solidification of the wax. Such staged heat control can be applied in three vertically oriented zones, namely: the lower base zone, the sensor package zone, and the upper wax supply and tamping zone. By applying different heating rates and heating time intervals to these zones, a vertical thermal gradient can be established in the wax melt so that it will solidify in a bottom-to-top sequence minimizing shrinkage in the two lower zones. By using distributed electrical heating within the body of wax, accurate heat cuntrol can be achieved and, when the two lower zones are ready to be solidified, the heating power to these zones may be removed while maintaining appropriate heating of the upper zone so that graded solidification is achieved from the base zone upward. Temperature sensors (thermistors) located in each zone serve to indicate the thermal changes produced by the electrical heating control. Upon cooling and solidification of the wax, the sensor package will be rigidly coupled to the bottom of the borehole for detecting seismic waves radiated from the reverse VSP seismic source. When all measurements are complete, the electrical heating elements still located within the wax embedment may be energized to melt the wax so that the sensor package and heating element assembly may be removed, leaving only the expendable wax in the borehole.

\section{Wax-Mc't Borehole Module and Sensor Signal Conditioner}

A seismic sensor module was designed to be installed in a shallow borehole having a nominal diameter of 6.25 inches. This module and its associated electrical heating elements and sensors are mounted on a lightweight frame capable of supporting the downhole assembly when lowered and raised in the borehole by means of a light-duty nylon line. Electrical cables, bundied onto the nylon line, supply power to the electrical heating elements, return the temperature sensor readouts to the surface, supply power to the three accelerometer sensor electronic circuits, and transmit the accelerometer output signals to the surface.

Figure 1 illustrates the general configuration of the downhole frame showing the placement of the accelerometer sensor unit and zonal heating elements. The accelerometer sensor package contains the triaxial array of accelerometers rigidly mounted in a solid PVC 
cylindrical mounting block and coated with a thin layer of polyurethane. The heater elements consist of \#16 AWG nichrome resistance wire supported on tubular ceramic insulators held in place on brass support rods. The entire frame is precast into a wax billet which contains the necessary amount of wax to fill the nominal 6.25-inch diameter borehole to a height of 2-3 inches above the top of the frame assembly.

\section{Laboratory Wax-Melt Experiments}

Laboratory experiments were conducted to test the wax-melt coupling technique and the wax-melting control process for borehole applications. For this purpose, the wax-meltcoupled seismic detector containing the sensor package and its surrounding heating elements was placed in a closed acrylic plastic tube five inches in diameter and tirree feet long and then immersed in water. Melied carnauba wax blended with smaller amounts of other vegetable waxes was then poured into the plastic tube. Upon cooling and solidification, the wax provided a rigid embedment of the seismic sensor package in the tube. The intimate coupling and the minimal degree of wax shrinkage were easily observed through the transparent tube.

The wax-melting process critical to recovery of the sensor assembly was tested by monitoring the wax heating time, the wax heating power, and the temperature of the wax embedment. Seven thermistors calibrated in the range of $100-250^{\circ} \mathrm{F}$ and located in each wax melt zone of the sensor package were used to monitor the thermal conditions in the wax.

The laboratory experiments demonstrated that, in order to gradually melt the wax surrounding the probe assembly in the water bath a maximum heating power of approximately 950 watts was required for one hour. In addition, the experimental results indicated that, by applying different heating power, a $10-15^{\circ} \mathrm{F}$ vertical thermal gradient could be established in the melted wax column. in this case, when the upper section of the wax was warmer than the lower section, cooling and solidification of the wax coupling occurred with minimum shrinkage of the wax embedment.

\section{THE REVERSE VSP TEST SYSTEM}

An experimental high-frequency reverse VSP system was devised to record threecomponent seismic data. This system included a borehole piezoelectric cylindrical bender source, a triaxial wax-melt sensor and a three-channel data acquisition system. The cylindrical bender transducer is a monopole source designed to operate in the frequency range of 500 $-4,000 \mathrm{~Hz}$.

The three-channel laboratory computer-based digital data acquisition system was used to record the triaxial seismic signals with $50 \mu \mathrm{sec}$ sampling and 12-bit analog-to-digital conversion in each channel. Sharp cut-off low-cut filters having adjustable cut-off frequency and $-60 \mathrm{Db} /$ octave stop-band attenuation are used in each signal channel to effectively remove the low frequency seismic signals whose wavelengths are too large to resolve the high-resolution details of interest. By setting these filters at a low cut-off frequency of about $400 \mathrm{~Hz}$, the entire conventional seismic frequency range is rejected so that the full dynamic range of 
the digital data acquisition system is available for recording high-resolution seismic signals. This low-frequency rejection process is important to the reverse VSP measurements since the particular seismic responses of interest are only resolved distinctively at the higher frequencies.

The wax-coupled triaxial accelerometer sensor was prepared for installation in a 6.25 inch diameter borehole by first casting it in a 5.5 -inch diameter cylindrical billet approximately 19 inches long. This cylinder length is sufficient to provide the excess amount of wax necessary to surround and embed the sensor package in the borehole after melting. Figure 2 shows the finished wax casting in a form ready to be placed in the borehole. This casting was installed in an open 24-m deep water-free borehole having a nominal diameter of 6.25 inches. The wax billet sensor package was lowered to the bottom of the borehole and electrical heating power of approximately 950 watts was applied for a time period of one hour at which time the wax billet melted and reached a final temperature of $100^{\circ} \mathrm{C}$ in its upper section. Heating power was then removed and the wax implant was allowed to cool and solidify.

\section{EVALUATION OF DOWNHOLE PLANTING TECHNIQUES}

\section{Shallow Test Formations}

Evaluation of two high-resolution borehole seismic detector probes was performed in boreholes located on the grounds of Southwest Research Institute. The shallow subsurface lithology is known to consist of layers of limestones, mudstones, shales, and dolomites. Seven boreholes are available which traverse the Anacacho Limestone from the surface to a depth of $64 \mathrm{~m}$, the Austin Chalk to a depth of $97 \mathrm{~m}$, and the Eagle Ford Shale to a depth of $129 \mathrm{~m}$. The holes then enter the Buda Limestone and continue to a total depth of $131 \mathrm{~m}$.

The Anacacho Limestone consists of layers of marly limestone sandwiched between layers of relatively cleaner limestone. The Austin Chalk is a 43-m thick layer of carbonate mudstone overlain by a $12-\mathrm{m}$ thick layer of marly limestone. The Eagle Ford Shale is a layer of blue-gray to black shale with an underlying layer of siltstone and fine sandstone. The Buda Limestone lies under the Eagle Ford Shale and consists of dense hard nodular limestone overlying a bed of clay. The boreholes do not penetrate through the Buda Limestone, but stop after extending about two meters into this hard limestone layer.

The lithology of the area continues (below borehole total depth) with the Georgetown Limestone consisting of dense argillaceous limestone overlying the Edwards Aquifer Group limestone and dolomite formation consisting of honeycombed limestone and dolomite interbedded with chalky porous limestone.

\section{Wax-Coupled Seismic Measurements}

Three-component seismic measurements were recorded using the cylindrical bender seismic source and the wax-embedded detector. The seismic source was placed in a $137-\mathrm{m}$ deep borehole located $20 \mathrm{~m}$ away from the $24-\mathrm{m}$ deep detector borehole. The detector probe 
was embedded with its X-axis sensor oriented approximately toward the source borehole. Seismic measurements were acquired using different source pulse signals in the frequency range of $750-3000 \mathrm{~Hz}$ and at several source depths ranging from 22 to $129 \mathrm{~m}$.

As an example of wax-coupled sensor responses, Figures $3 \mathrm{a}, 3 \mathrm{~b}$, and $3 \mathrm{c}$ illustrate three-component reverse VSP seismograms at $750 \mathrm{~Hz}$. Figure $3 \mathrm{a}$ also shows the different geological units penetrated by the source borehole. The seismograms show that the principal direction of the particle motion is in the $x$-direction, since most of the energy transmitted by the source appears as strong events on the $x$-component seismogram. The direction of the particle motion can also be observed in hodograms constructed from the three-component seismic traces. For example, Figure 4 shows three-component waveforms of pulse source signals in the range of $750-1500 \mathrm{~Hz}$ at a source depth of $48 \mathrm{~m}$. These waveforms were used to calculate the instantaneous signal propagation vectors as illustrated by three-axis hodogram plots in Figure 5. These hodograms show that the principal particle motion is approximately parallel to the $x-z$ plane and little particle motion is in the $y-z$ plane. The hodograms can be used as a check for potential spurious response effects in the probe by examining the quality of the linear polarization pattern for compressional waves. This check is very sensitive the magnitude of the probe resonances and their detrimental effects on the accelerometer records. In the present example, the three-dimensional hodograms show the relatively clear linear particle motion expected from the controlled test conditions. The particle motion pattem in Figure 5 confirms the near-ideal properties of rigid coupling produced by the wax-embedded detector.

In order to evaluate the reliability of the seismic measurements using the waxembedded detector, $x$-component seismograms are correlated with the shallow subsurface lithology at the borehole test facility. Figures 6 and 7 illustrate seismograms obtained for source pulse signals in the range of $750-1500 \mathrm{~Hz}$. In Figure 6, the seismograms associated with the top limestone layer illustrate a transmitted converted PS wave developed at the marly limestone/clean limestone contact with the source located in the limestone layer. This event consists of seismic waves in which the time intervals between the direct P-wave and the converted PS wave increase as the source-detector distance increases. In general, the events associated with transmitted waves and converted waves exhibit a characteristic: seismic signature which is related to the contact and its attitude relative to the seismic source. For instance, the high-frequency horizontal component seismogram at a source center frequency of $1000 \mathrm{~Hz}$ provides good resolution of the converted waves, which makes identification of the contact easier.

The chalky limestone region is a water saturated low-velocity formation for which seismic responses for pulse signals in the frequency range of $750-1500 \mathrm{~Hz}$ are given in Figure 7. When the seismic source is placed below the cleaner limestone region (in the water table) the angle of incident of the direct $\mathrm{P}$-wave is quite steep resulting only in $\mathrm{P}$-waves arriving at the detector position. In comparison, when the source is placed in the low-velocity Austin chalk, a compressional head wave in the overlying layer arrives at the detector before the direct P-wave traveling through the Austin chalk. The seismic events formed by the head waves correlates with the limestone/Austin chalk boundary which separates the top limestone layer of higher velocity and the low-velocity bottom formation. As a conclusion, the moveout of the direct $\mathrm{P}$-wave avent in the $\mathrm{x}$-component seismogram shows that the velocity gradient 
decreases as the source detector separation increases and, therefore, there is a distinctive change in velocity gradient between the surface limestone layer and the Austin chalk formation.

\section{Comparison Between Pneumatically Coupled and Wax-Embedded Detectors}

An experimental 3-component borehole seismic detector employing pneumatic borehole coupling was tested in the same shallow boreholes. This detector consists of a lightweight PVC sleeve 4.5 inches in diameter containing a triaxial accelerorneter array identical to that used in the wax-embedded detector. A $9 \times 6$-inch rectangular sheet of nubber is clamped at its edges to cover approximately 25 percent of the outer surface of the PVC sleeve and is capable of being inflated at an inlet inside the PVC sleeve via an air pressure hose from the surface. This device, weighing about eight pounds, can be clamped in boreholes ranging from 5 to 7 inches in diameter to achieve borehole locking forces up to 150 pounds; a factor of more than 20 times the total weight of the detector package.

Figure 8(a) illustrates three-component pneumatically coupled seismic waveforms recorded for source pulse signals in the frequency range of $1000-2000 \mathrm{~Hz}$ for a source depth of $22 \mathrm{~m}$. To evaluate the pneumatically coupled detector response, wax-embedded detector seismic waveforms were used as reference measurements for the same source depth and frequency range. Figure 9 shows the comparable 3-component wax-embedded detector waveforms for a source depth of $22 \mathrm{~m}$. The $x$-component pneumatically coupled seismogram and the corresponding $x$-component wax-coupled seismogram, recorded for several source depths ranging from $22 \mathrm{~m}$ to $81 \mathrm{~m}$ at $2000 \mathrm{~Hz}$, are shown in Figure 10.

A comparison of the pneumatic-and wax-coupled sensor waveforms indicates that resonances in the pneumatically coupled responses mask the transmitted converted PS waves which are clearly observed in the corresponding wax-coupled waveforms. These resonances are strong in the $2000 \mathrm{~Hz}$ waveforms but were found to decrease significantly when the source pulse frequency was reduzed. The $y$-component waveforms appear to be less affected by the pneumatically clamped detector resonances than the $x$ and $z$ components since the direct $P$ waves and converted $P$ waves are clearly observed in the $y$-component waveforms. The seismic waveforms shown in Figure 10 are in response to three-cycle time domain source pulses rather than the two-cycle source pulse signal used in the wax-embedded detector tests.

Although resonance effects are evident in most of the traces in the $x$-component pneumatically coupled seismogram shown in Figure 10(a), the waveforms are dominated by direct $P$ waves in the form of short-duration pulses. The clarity of these waveforms lead to the conclusion that the coupling obtained with the pneumatically clamped detector is quite reasonably comparable to the more ideal reference coupling obtained with the wax-embedded detector.

Finally, after the wax-coupled detector field experiments were completed, the waxcoupling medium was transformed from a solid state to a liquid state to allow the detector probe to be decoupled and removed from the borehole. The heat application time and the heating power required to melt the wax was seven hours at a power of 950 watts after which the detector was easily lifted out of the borehole. This extended downhole recovery time, 
compared with the one-hour emplacement time, is caused by the heat capacity of the surrounding moist rock formation at the bottom of the borehole.

\section{CONCLUSIONS}

The development and evaluation of downhole planting techniques and instrumentation tests under controlled conditions for high-resolution reverse VSP measurements described in this paper have yielded important results which demonstrate that borehole coupled detector probes readily respond to high-frequency seismic wave propagation through the formations. The results demonstrated that seismic waves in the frequency range of about $500 \mathrm{~Hz}$ to $2000 \mathrm{~Hz}$ can be detected using three-component detector probes containing high-frequency accelerometers.

An ideally coupled wax-embedded reference detector was successfully developed and tested. Laboratory experiments and field tests demonstrated that the wax-coupling technique achieved the desirable results of rigid conformal borehole coupling and the ability to recover the nonexpendable acceleration detector probe after the seismic measurements were complete. The wax-coupled seismograms and hodograms exhibited undistorted linear particle motions characteristic of near-ideal properties of rigid coupling produced by a detector free of any modal resonances in the coupled detector package.

A comparison of the pneumatically coupled and the wax-embedded detector waveforms indicated that the pneumatically coupled sensor response is reasonably comparable with that of the more ideal reference coupling obtained with the wax-coupled detector. These results suggest that the pneumatically clamped probe is practical and appropriate for use in high-resolution reverse VSP measurements. Pneumatic operating limitations of this detector in boreholes deeper than about $30 \mathrm{~m}$ can be overcome by converting the pneumatic clamping mechanism to an equally simple hydraulic clamping arrangement and by incorporating a means for orienting the three-component sensor probe in a known azimuthal direction.

\section{ACKNOWLEDGEMENT}

Principal support of this work was provided by the U. S. Department of Energy Geoscience Research Program under DOE Contract No. DE-AC22-89-C14473. The assistance of Dr. Chandra Nautiyal and permission granted by the DOE to publish this interim technical study is gratefully acknowledged and appreciated.

\section{REFERENCES}

de Montmollin, V., 1988, Shaker Tests on Downhole Seismic Tools: Geophysics, V. 53, No. 9. pp. 1160-1168.

Parra, J.O., and Owen, T.E., 1990, Demonstration of High-Resolution Inverse VSP for Reservoir Characterization Applications, Task I-Development and Evaluation of 
Detector Planting Techniques: Annual Status Rept., U.S. Dept. of Energy, Contract No. DE-AC22-89-C14473, SwRI Proj. 15-3200.

Tan, T.H., 1987, Reciprocity Theorem Applied to the Giophone-Ground Coupling Problem: Geophysics, V. 52, No. 12, pp. 1715-1717.

Wuenschel, P.C., 1988, Removal of the Detector-Ground Coupling Effect in the Vertical Seismic Profiling Environment: Geophysics, V. 53, No. 3, pp. 359-364.

Wuenschel, P.C., 1976, The Vertical Seismic Array in Reflection Seismology-Some Experimental Studies: Geophysics, V. 41, No. , pp. 219-232. 


\section{FIGURE CAPTIONS}

Figure 1. Lightweight sensor frame and heater elements.

Figure 2. Prototype morel of wax-melt borehole seismi: detector probe ready for downhole installation.

Figure 3. Three-component seismograms. Seismic data recorded with the wax-embedded detector. Shot points obtained with $750 \mathrm{~Hz}$ source center frequency. (a) Xcomponent. (b) Y-component. (c) Z-component.

Figure 4. Three-component waveforms recorded with the wax-embedded detector. The source depth was $48 \mathrm{~m}$ and the detector depth was $22 \mathrm{~m}$. Shot points abtained at source center frequencies of: (a) $750 \mathrm{~Hz}$; (b) $1000 \mathrm{~Hz}$; and (c) $1500 \mathrm{~Hz}$.

Figure 5. Instantaneous signal propagation vectors as three-axis hodogram plots. Seismic waveforms recorded with the wax-embedded detector. Hodograms are constructed from the seismic waveforms given in Figure 4. Shot points obtained at source center frequencies of: (a) $750 \mathrm{~Hz}$; (b) $1000 \mathrm{~Hz}$; and (c) $1500 \mathrm{~Hz}$.

Figure 6. X-component wax-embedded detector seismograms. Seismic events associated with the top limestone layers. Shot poinis obtained at source center frequencies of: (a) $750 \mathrm{~Hz}$; (b) $1000 \mathrm{~Hz}$; and (c) $1500 \mathrm{~Hz}$.

Figure 7. X-component wax-embedded detector seismograms. Seismic events associated with water-saturated low-velocity Austin chalk formation. Shot points obtained at source center frequencies of: (a) $750 \mathrm{~Hz}$, (b) $1000 \mathrm{~Hz}$; and (c) $1500 \mathrm{~Hz}$.

Figure 8. Three-component waveforms recorded with the pneumatically clamped detector. Source depth and detector depth were $22 \mathrm{~m}$. Shot points obtained at source center frequencies of: (a) $1000 \mathrm{~Hz}$; (b) $1500 \mathrm{~Hz}$; and (c) $2000 \mathrm{~Hz}$.

Figure 9. Three-Component waveforms recorded with the wax-embedded detector. Source depth and detector depth were $22 \mathrm{~m}$. Shot points obtained at source center frequencies of: (a) $1000 \mathrm{~Hz}$; (b) $1500 \mathrm{~Hz}$; and (c) $2000 \mathrm{~Hz}$.

Figure 10. X-component seismograms. Shot points obtained with a $2000 \mathrm{~Hz}$ source center frequency. Seismic waveforms recorded using: (a) pneumatically clamped detector and (b) wax-embedded deiector. 


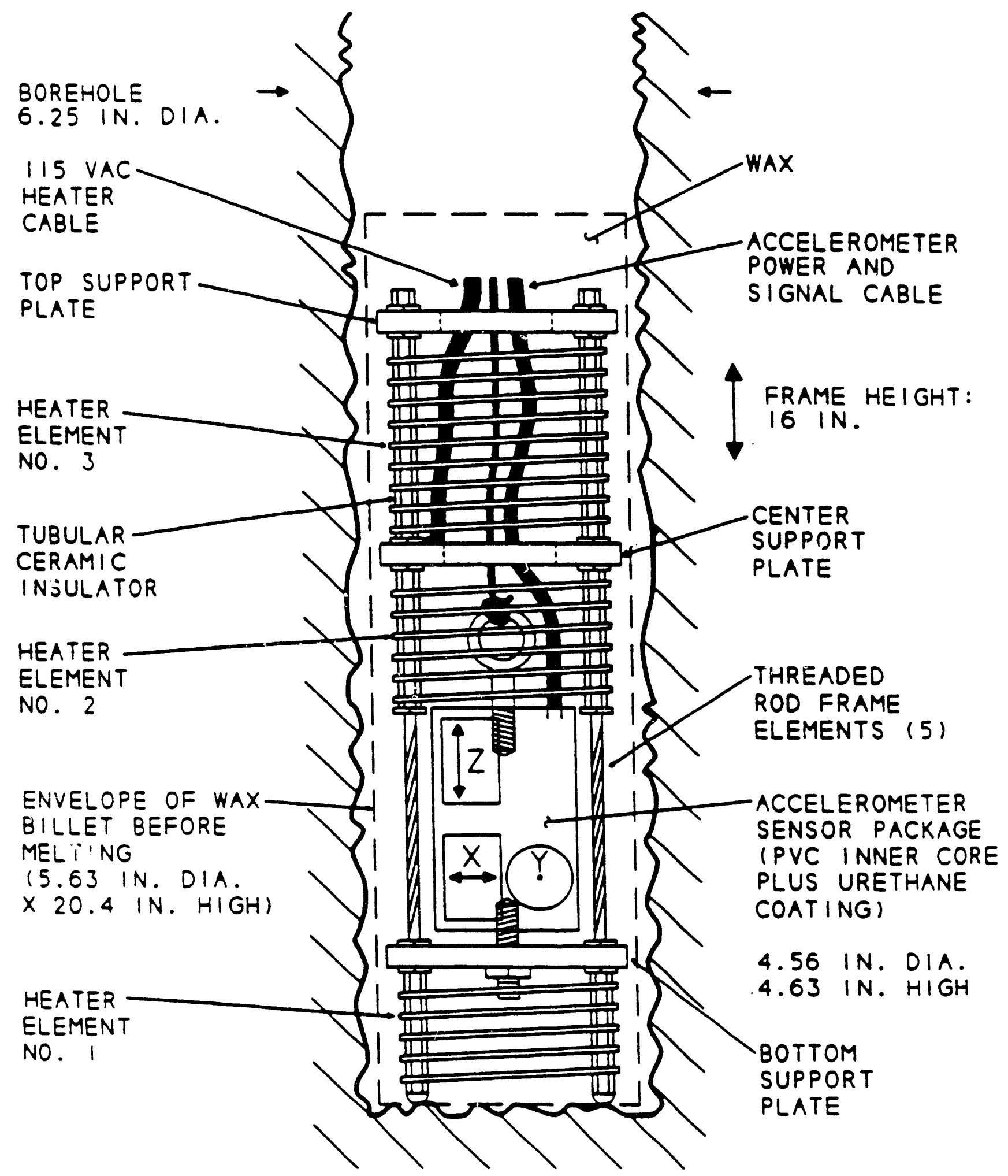

FIGURE 1. 


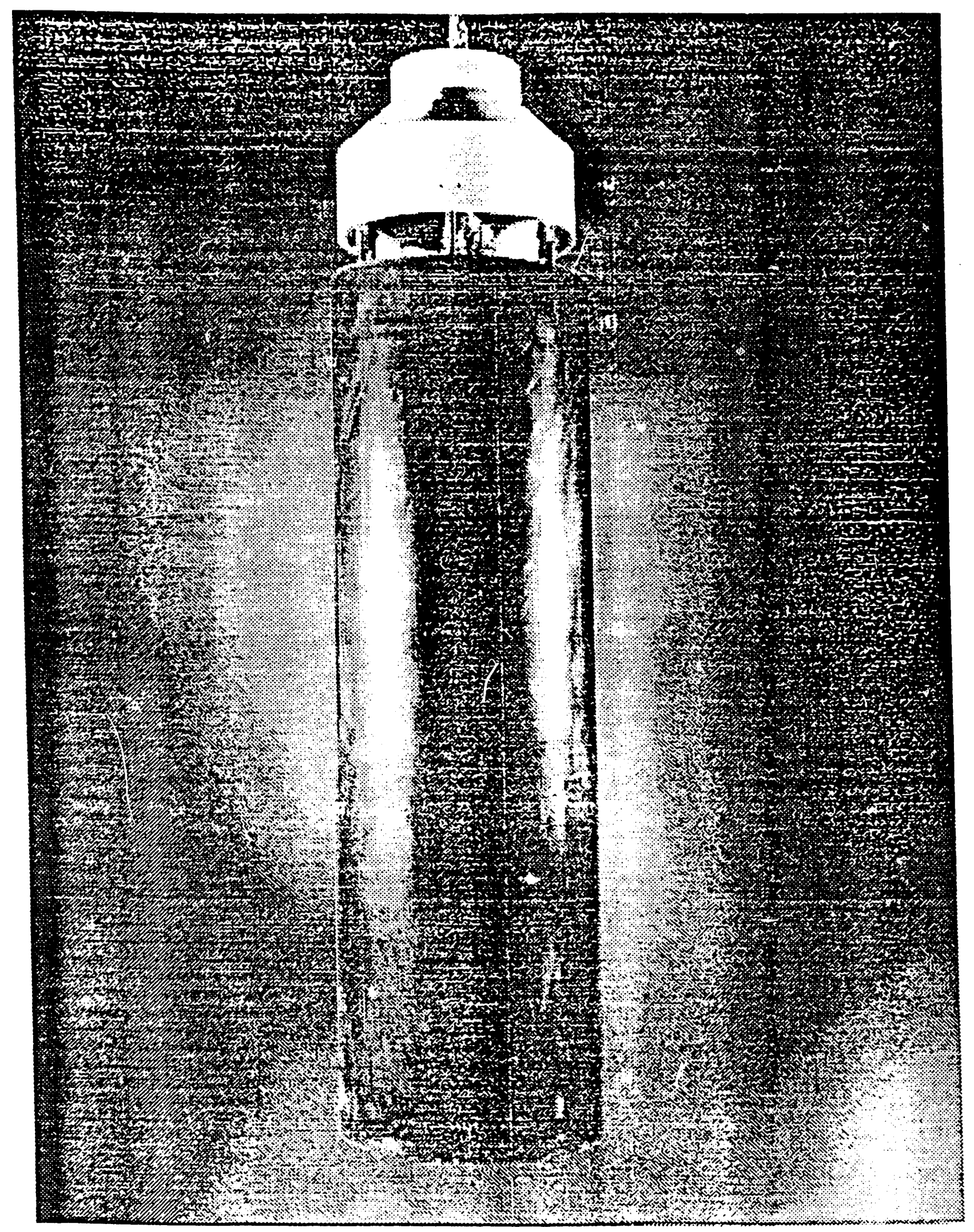

FIGURE 2. 

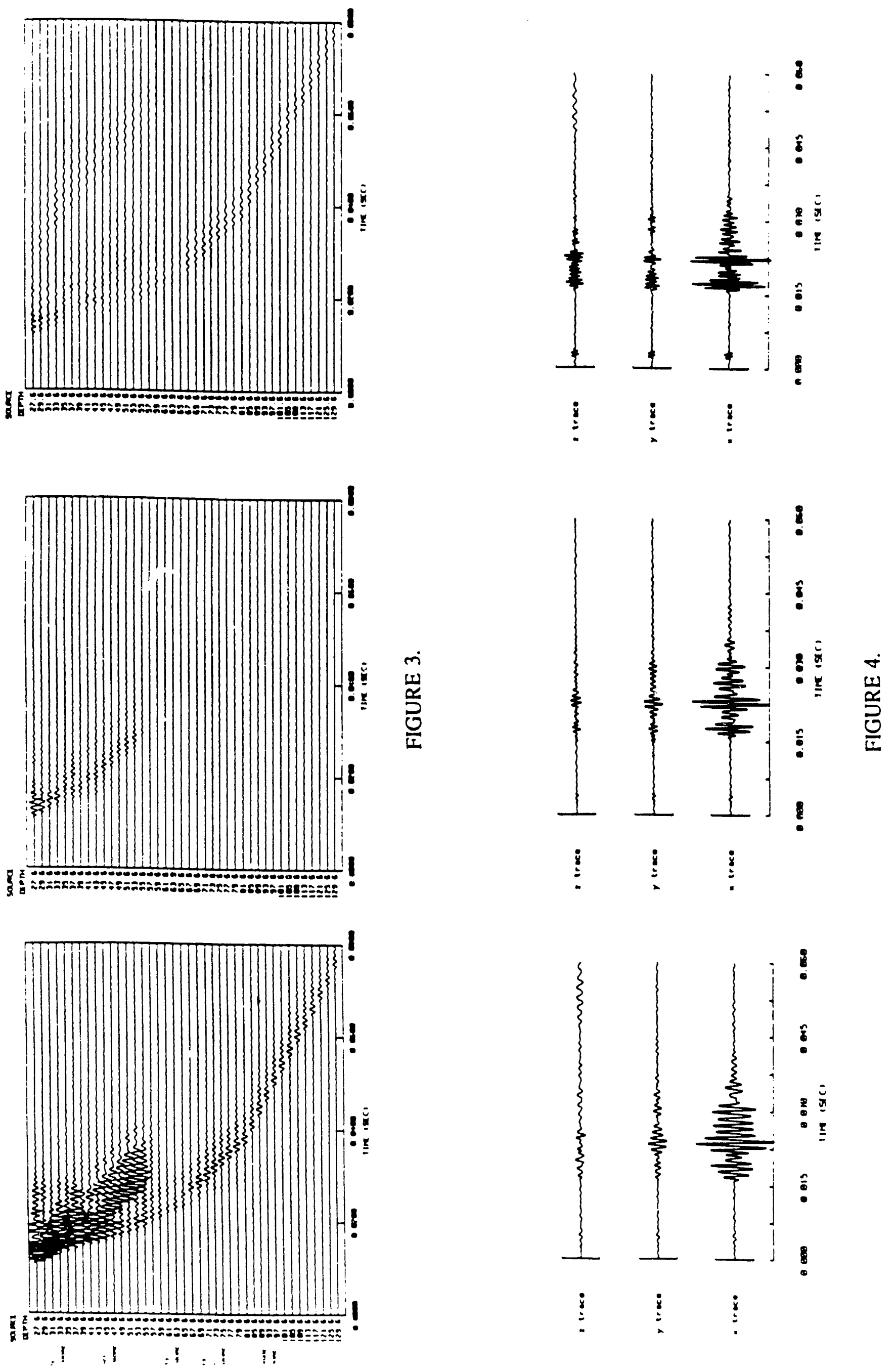

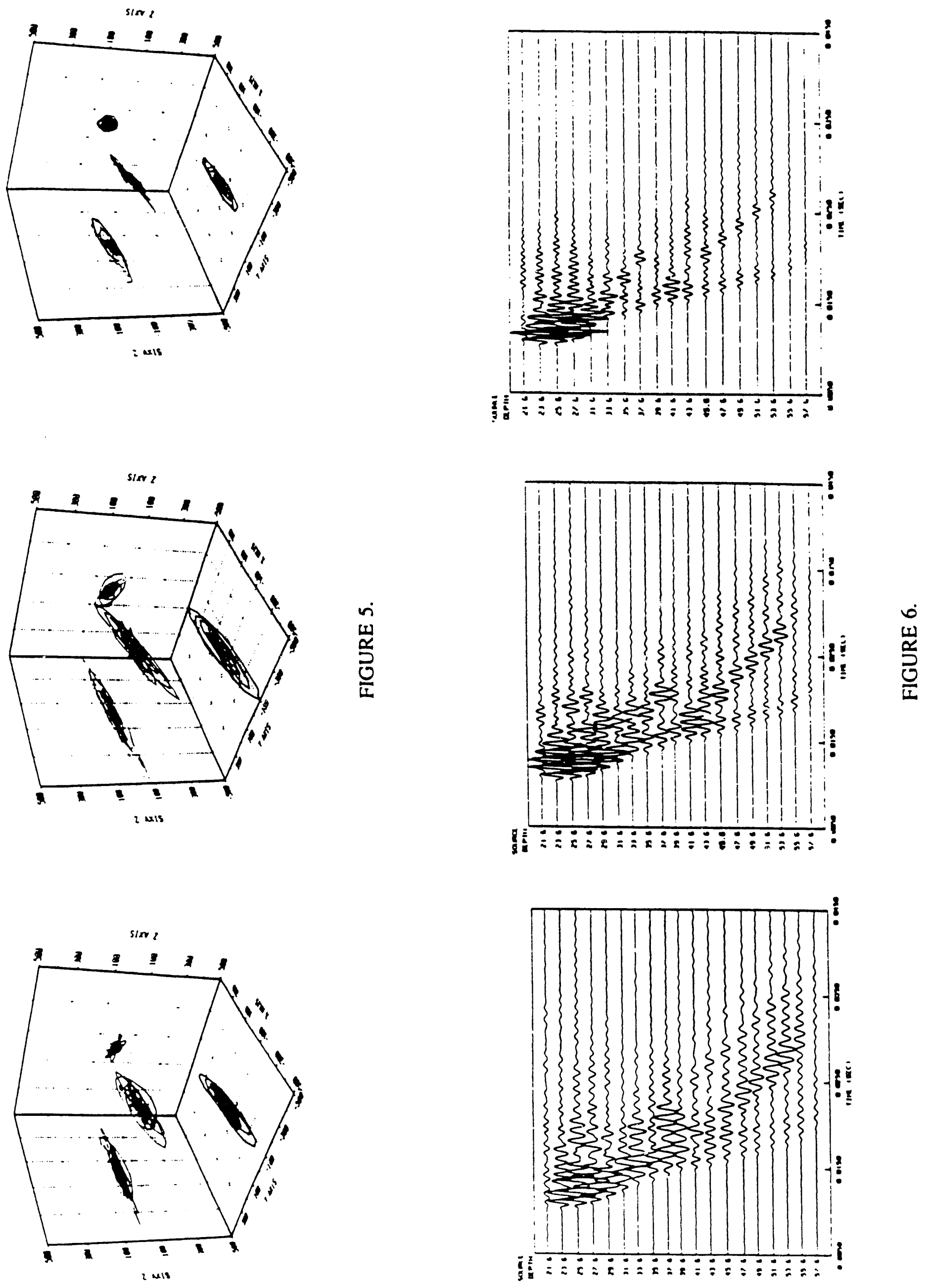

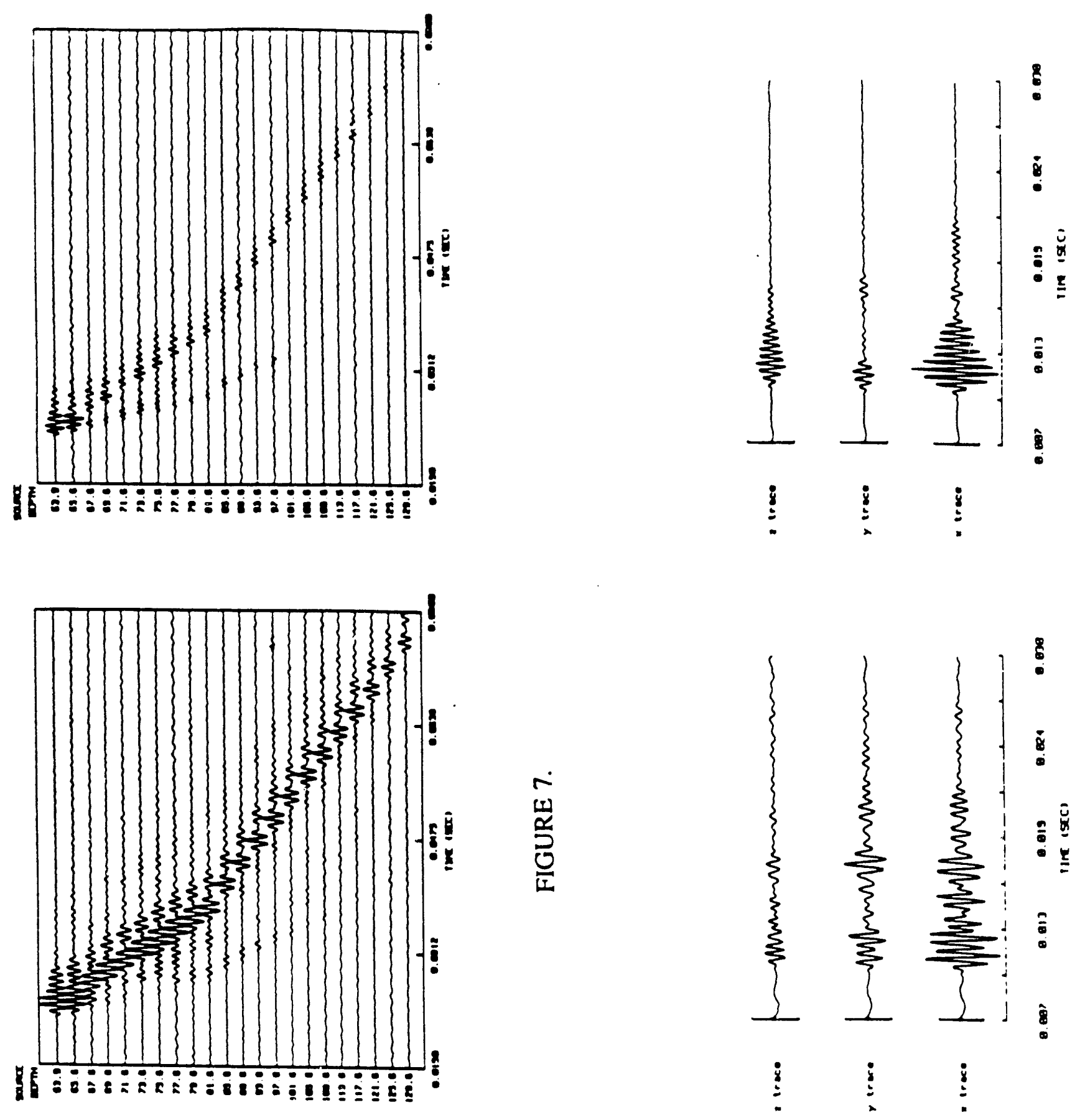

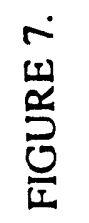
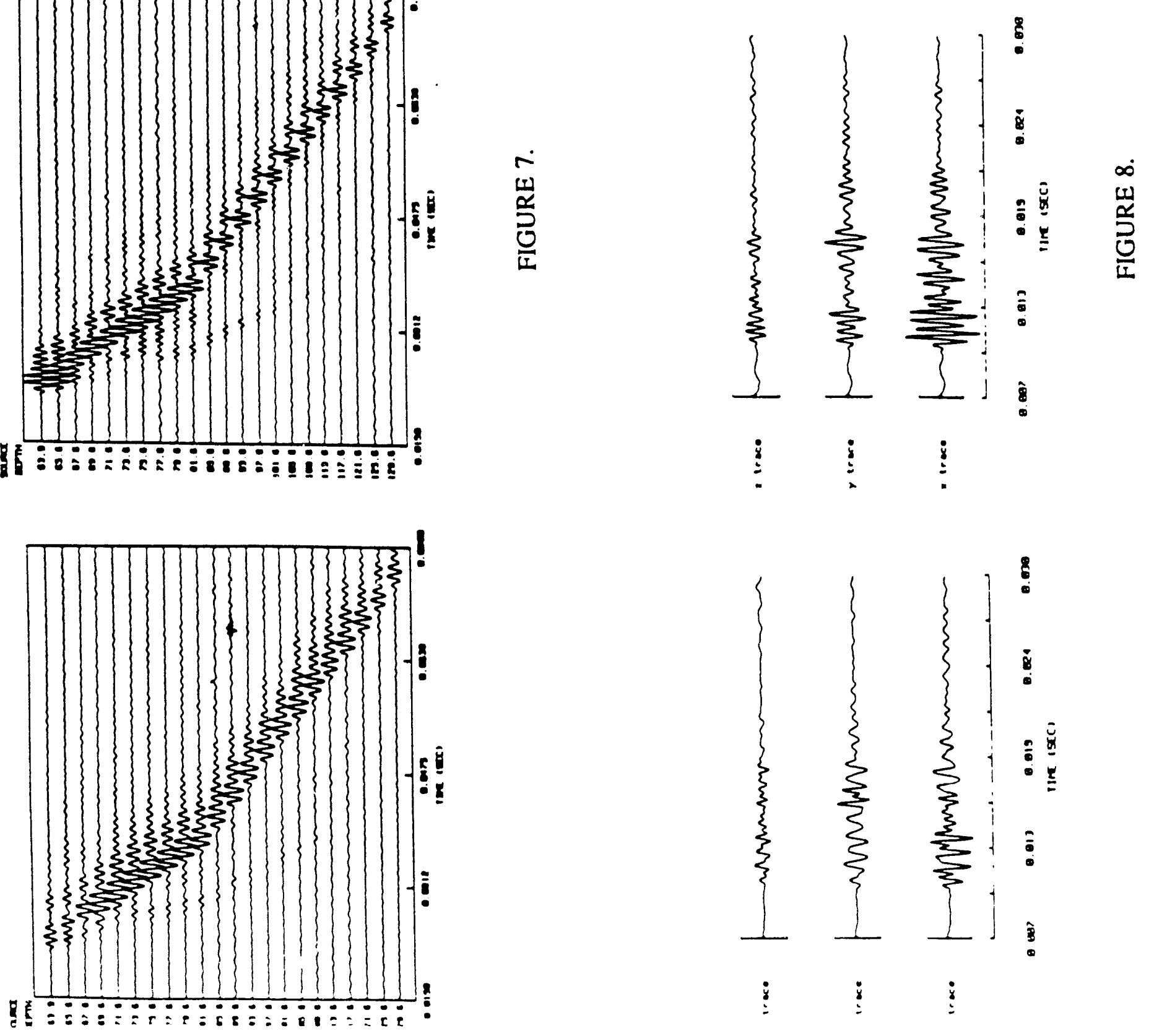

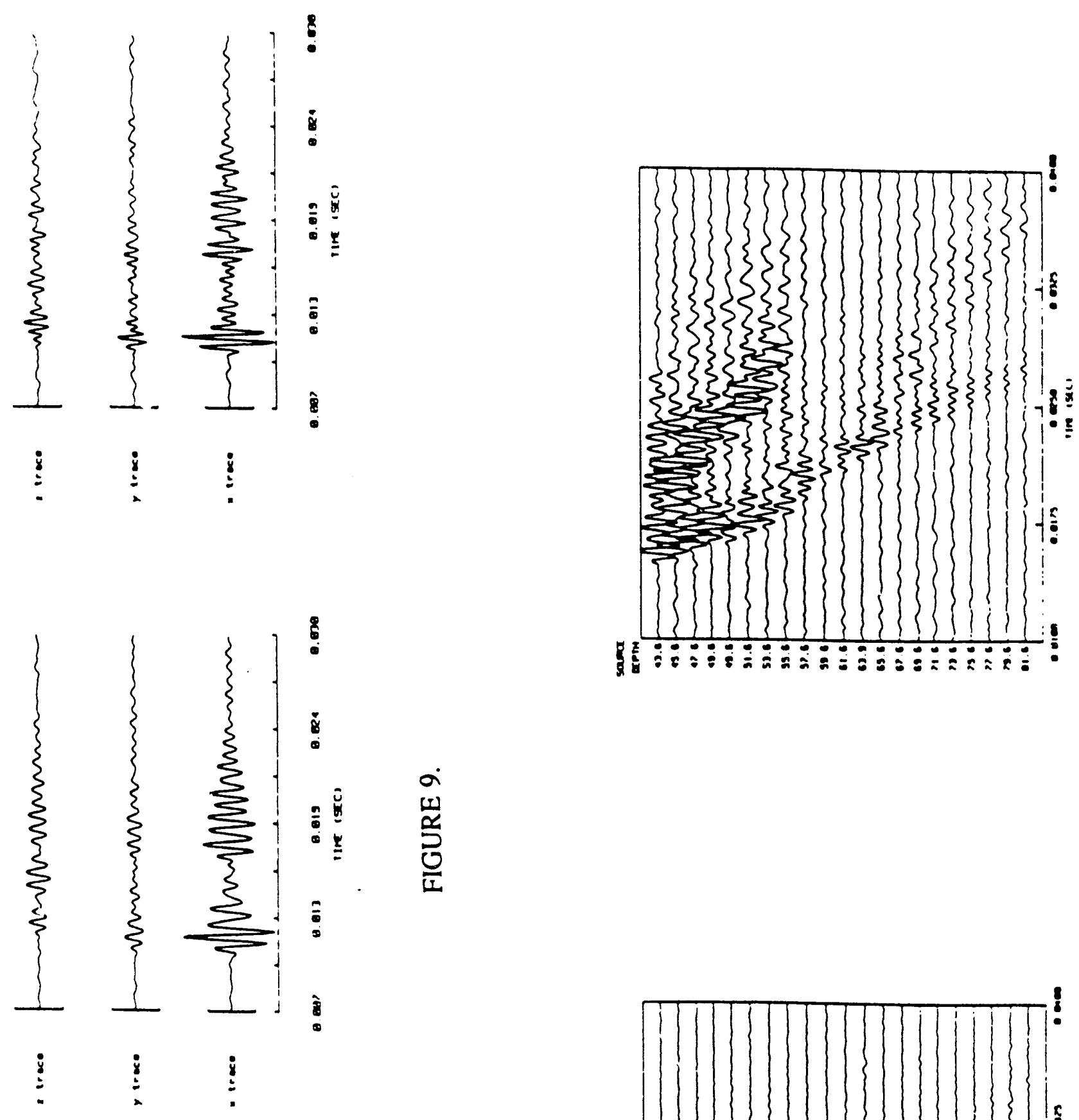

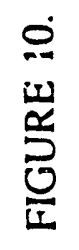
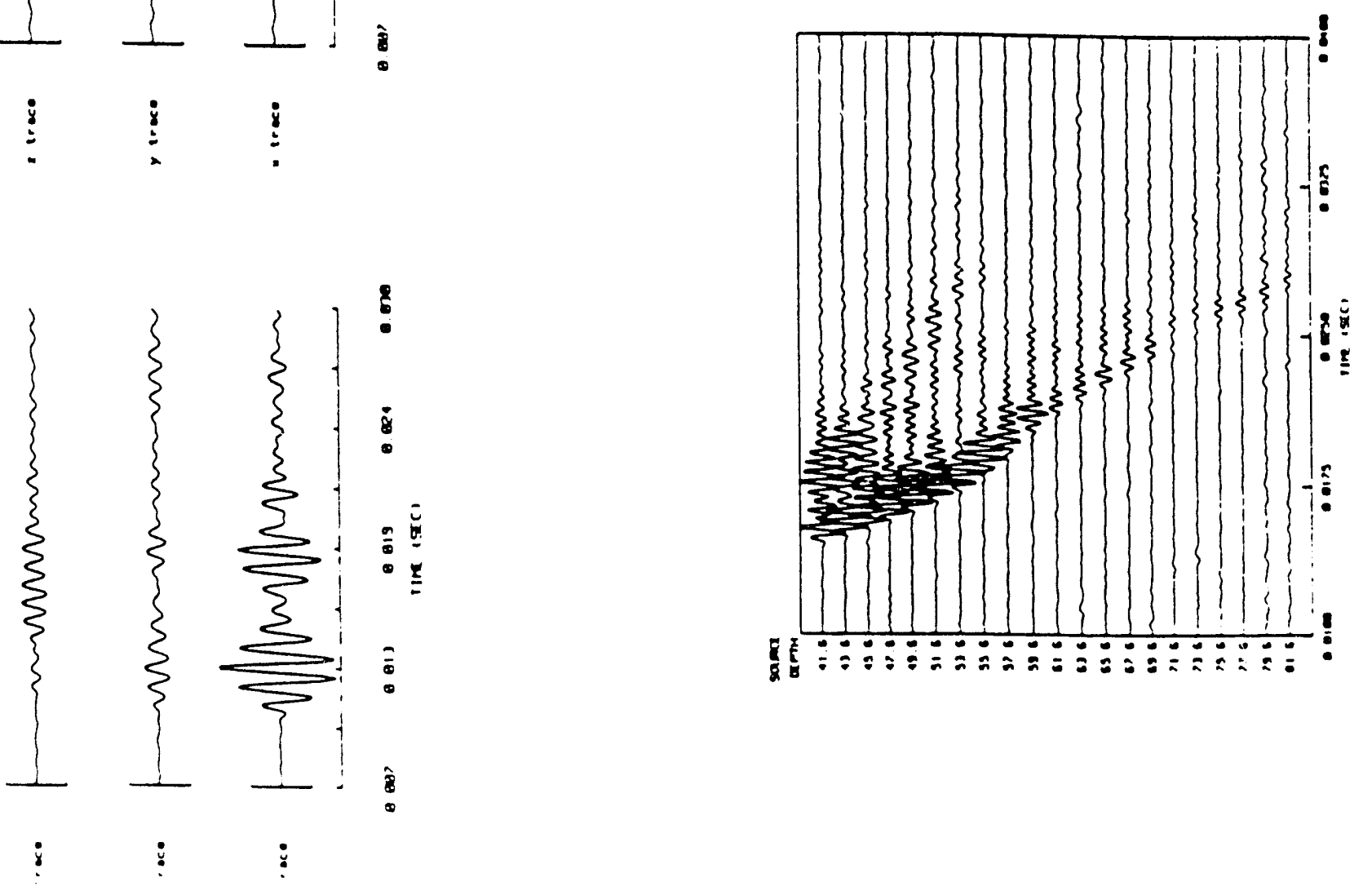

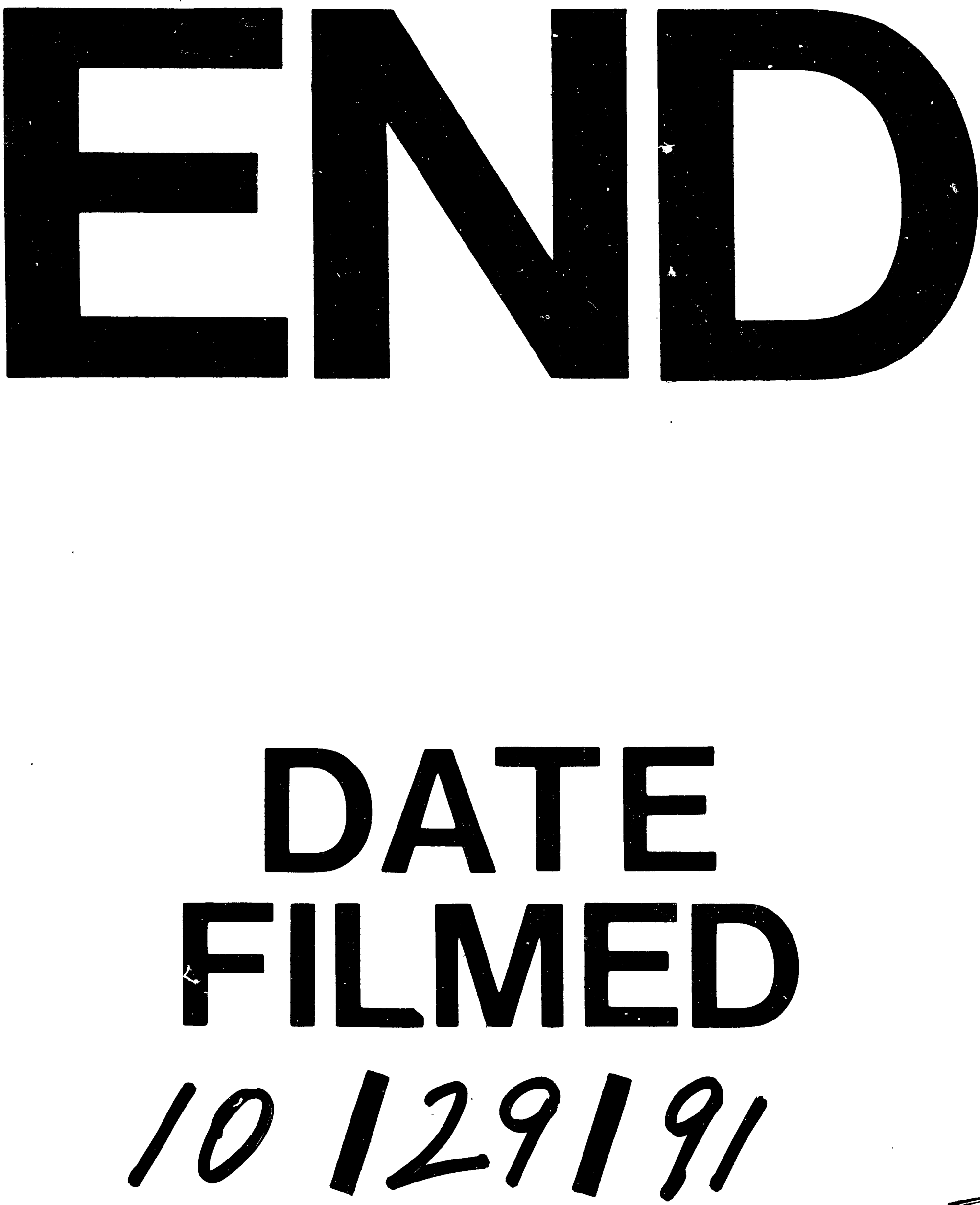